\title{
Patterns of Technology Transfer in Chinese Hotspots of Innovative Development- The Perspective of the Recipient Firms
}

\author{
Henning Kroll, Esther Schnabl \\ Competence Center Policy and Regions, Fraunhofer Institute for Systems and Innovation Research ISI, \\ Karlsruhe, Germany \\ Email: henning.kroll@isi.fraunhofer.de
}

Received 30 April 2014; revised 3 June 2014; accepted 13 June 2014

Copyright (C) 2014 by authors and Scientific Research Publishing Inc.

This work is licensed under the Creative Commons Attribution International License (CC BY). http://creativecommons.org/licenses/by/4.0/

c) (i) Open Access

\begin{abstract}
In China, as in other countries, pre-competitive research constitutes the basis of techno-economic development beyond imitation and adaptation. While acknowledging the nation's concerted efforts to improve the situation, most empirical accounts of science-industry linkages in China remain sceptical about local universities' ability to meaningfully transfer knowledge and technologies. Against this background, we change perspective and analyse the perceptions of selected technology-oriented firms in Beijing. Interestingly, we find that there is a notable core of technology firms with fairly close linkages to universities and research institutions.
\end{abstract}

Keywords

Technology Transfer, Beijing, China, Germany, Universities

\section{Introduction}

As other countries which confronted institutional legacies of a planned economy, China had to substantially reform and adapt its higher education system in the course of the 1980s and the 1990s (OECD, 2008; Wu, 2010a). Institutions that used to be mere teaching facilities until the late 1970s gradually resumed their scientific activities and in some cases developed into internationally acknowledged hubs of cutting-edge research (Frietsch et al., 2008; Yang \& Welch 2012). More importantly for this paper, however, the implications of this transformation have not remained limited to the realm of scientific merit, but have also turned Chinese universities into more relevant sources of knowledge for the business sector than is common in other developing nations (Intarakumnerd et al., 2002; Liefner \& Schiller, 2008).

How to cite this paper: Kroll, H., \& Schnabl, E. (2014). Patterns of Technology Transfer in Chinese Hotspots of Innovative Development-The Perspective of the Recipient Firms. Chinese Studies, 3, 83-95.

http://dx.doi.org/10.4236/chnstd.2014.33012 
Furthermore, China's rapid development did not only come with a renewed push for scientific excellence but also with quickly developing ambitions with regard to technological upgrading in the domestic industrial sector (Jin et al., 2008; Lee et al., 2011). The pre-reform system's approach of relying on freely available research results of public research institutes (Segal, 2003) predictably failed (Chen \& Kenney, 2007). During the process of institutional transformation, therefore, many of these institutes were either privatised straight away or substantially reformed (OECD, 2008). These reforms, however, did progress fast enough to satisfy the rapidly emerging demands of the national industry (Kroll \& Schiller, 2010). As a result and in part expedited by a parallel decrease in their basic funding for research (Chen \& Kenney, 2007), Chinese universities were confronted with substantial opportunities in different areas of what the academic discussion has come to label the "third role" (Kroll \& Liefner, 2008; Wu, 2010a). Already involved in a process of transformation since the 1980s, they were arguably able to adapt to this novel role in the field of applied R \& D faster than public research organisations, even if they, too, had to overcome notable internal challenges before all internal stakeholders were ready to accept university-industry relations as part of their mission (Kroll \& Liefner, 2008; Wu, 2010a). In any case, the industrial share of funding for university R \& D has been and remains higher than that of funding for public research activities at many of those other public research institutions which, with a view to their mission, should deliver more applied results (Kroll \& Schiller, 2010). In addition, the intensity of those co-operations with the private sector that can be evidenced by co-patents has visibly increased (Motohashi, 2008).

That notwithstanding, much of the literature underlines that the Chinese system of technology transfer has developed quite particular, and not always beneficial, features during the nation's gradual process of institutional reform. In particular, Chinese universities have focused on very entrepreneurial approaches to commercialisation and technology transfer, while market-oriented co-operative relations have taken longer to become effective (Gu, 1999; Kroll \& Liefner, 2008) One prominent element of this entrepreneurial approach are the "academy-run” or "spin-around” firms (Eun et al., 2006; Kondo, 2003), institutionally invested and dependent firms that have emerged side by side with actual spin-offs in China (Eun \& Lee, 2010; Kroll \& Liefner, 2008). While some studies underline that these structural tendencies persist until today (Wu \& Zhou, 2012), others (Guan et al., 2005; Motohashi \& Yun, 2007; Tagscherer et al., 2012) point out that there is no evidence suggesting that university-industry co-operations in China are limited to, or even very focused on, co-operations with such newly set-up firms. Among other studies, a 2009 survey of 21 universities and 31 companies in Beijing, Tianjin and Hebei unambiguously demonstrated that partners from science and industry maintained quite different forms of co-operations from small-scale project-oriented contract research, the strategic set-up of joint science-industry research centres in high-tech industries, to the formation of long-term national alliances for pre-competitive R \& D in defence-related or heavy industry (Tagscherer et al., 2012: p. 35). In fact, Chinese universities seem to engage in a much larger part of the broad array of possible university-industry relations (D'Este \& Patel, 2007; Kodama \& Branscomb, 1999) and fulfill a much broader set of functions in their region (Uyarra, 2010) than commonly acknowledged (Chen \& Kenney, 2007; Motohashi \& Yun, 2007; Quan, 2010; Wu, 2010a).

What remains unanswered, however, is to what extent the potential recipients of technology transfers in China's hot-spots of innovation are still facing the specifically Chinese obstacles mentioned in earlier studies (Cao, 2004). Even though arguably disconnected from other parts of the broader industrial system, these hot-spots of development still undisputedly constitute one of the dynamic cores of the Chinese national innovation system, remain central to building China's domestic technological capabilities and, in the long term, may well generate more relevant spill over effects than today (Kroll \& Schiller, 2010; Lee et al., 2011; Zhao \& Richards, 2012). For the moment, however, the situation on the "islands of innovation" remains too specific to draw on general studies on technology transfer in the Chinese economy to improve our understanding of these particular environments. Consequently, the authors see merit in a study that is aimed at illustrating how the network of knowledge exchange has evolved in Beijing as one of the core locations that served as a driver of the Chinese national innovation system in the last decade.

The innovation system of Beijing is characterised by a strong public research base and many innovative firms and has in a particular manner inspired and dominated the academic discussion on technology transfer in China. While many foreign firms have formal representations or even research centres in Beijing as the nation's academic centre and capital the role of innovative production in foreign invested enterprises is much lower than e.g. in Shanghai or the Pearl River Delta (Kroll, 2010). To the contrary, the local innovation system is dominated by domestic firms both state-owned conglomerates and privately owned spin-offs. While the local SME sector is somewhat less vibrant than e.g. in Zhejiang or Jiangsu, many high-tech enterprises have emerged in the envi- 
ronment of the nation's leading and have in the course of the past decade grown with regard to not only technological capacity, but also actual sales and international reputation. Mainly, it is this population of advanced, often private firms that will be addressed by this paper's analysis.

\section{Conceptual Approach and Hypotheses}

For at least two decades, Chinese policy making has sought to develop the national business sector's technoeconomic capabilities beyond imitation and adaptation (Chen \& Kenney, 2007; Frietsch \& Schüller, 2010; OECD, 2008). Beyond prestige related considerations, one key political rationale behind this certainly is that business models based on innovation instead of labour cost competition enable Chinese firms to pay higher wages and thus, indirectly, safeguard societal well-being. Accordingly, pre-competitive research and technology transfer have been high on the central government's agenda since at least the 1980s (Cao et al., 2006; Chen \& Kenney, 2007). On the contrary, from an individual firm's perspective investment in technological upgrading only becomes relevant when it promises to yield tangible additional opportunities in terms of profit or growth (Dosi, 1988). In the 1990s and early 2000s, the market mechanism as such did not provide incentives so that Chinese firms could compete based on low labour cost or regulatory arbitrage with regard to for example pollution, and rely on technological imports from abroad (Chen, 2007; Lee et al., 2011). To some extent, undoubtedly, some of these incentive frameworks continue to persist until today, in particular in manufacturing regions like the Pearl River Delta (Kroll \& Schiller, 2012; Schiller, 2011). In recent years, however, this established situation has come under pressure by rising wages, tightening regulations, as well as an increasingly discerning and affluent customer base (Asian Development Bank (ADB), 2010; Lee et al., 2011). As a result, more and more companies in the affluent urban centres have successfully demonstrated that money can just as well be made by producing technologically more advanced and higher-quality products even if this requires drawing on a well-educated, more expensive workforce (Altenburg et al., 2008; Wang \& Zhou, 2013).

In parallel, more and more Chinese universities have developed to a point where they have become relevant sources of forward engineering (Frietsch et al., 2008; Lee et al., 2011). Evidently, Chinese firms have been making active use of these opportunities (Motohashi, 2008; Motohashi \& Yun, 2007) which in turn helped them to improve their own technological capacity and their ability to innovate (Brehm \& Lundin, 2012; Fu et al., 2012; Guan et al., 2005; Tagscherer et al., 2012). In the late 2000s and early 2010s, therefore, the formerly poor match of technology supply and demand (Kroll \& Schiller, 2010) improved while, in parallel, the national government reinforced its investments in science, technology and innovation (Cao et al., 2006; Lee et al., 2011; OECD, 2008). Moreover, university-industry relations have in some regions been the backbone of the regional technology sector from its outset, even during the planned economy era (Chen \& Kenney, 2007; Segal, 2003; Zhao \& Richards, 2012). As a result, these locations are a priori endowed with a much denser local network between the university and the industrial sector (Guan et al., 2005; Tagscherer et al., 2012). As Fu et al. (2012) rightly point out, however, these networks have to be understood in Chinese terms as guanxi-long-standing personal relations. While this network of inter-personal relations may create an environment of trust, it does not necessarily ensure an effective, dynamic and viable network of inter-business relations. Even when key people know each other well, they may not necessarily be knowledgeable about the implementation of technology transfer or free to act as they see fit. In the past decade, for example, the effectiveness of the network, which existed even then, remained severely hampered by deficiencies such as low absorptive capabilities in local firms, i.e. a limited ability to process and profit from available knowledge (Cohen \& Levinthal, 1990), unclear ownership rights, lack of venture capital, and the government's interventionist approach to technology policy (Cao, 2004). In more general terms, it has been argued that the existing networks cannot become effective without the right incentive systems and framework conditions (Wu \& Zhou, 2012).

It is also important to note that the dynamic of the local system of technology transfer does not depend on the technology providers alone, but at least to the same extent on the potential recipients of technology transfers (Bozeman, 2000, Bozeman et al., 2013). This was empirically confirmed for the case of China a few years ago (Cao, 2004). Hence, it has to be regarded as a deficit that the majority of recent studies on the system of technology transfer in China's hotspots of innovation have tended to focus on the perspective of the technology providers and taken a public research perspective (Wu \& Zhou, 2012; Wu, 2010b). As a result, it is mainly the perspective of the firm that remains missing from the overall picture-even though the potential of firm-based studies has unambiguously been demonstrated on a more general level (e.g. Brehm \& Lundin, 2012; Motoha \& Yun, 2007). 
In order to evaluate the current state of development of knowledge exchange and technology transfer in China's hotspots of innovative development, our analysis will have to focus on a sample of enterprises in Beijing that are part of the established local network and thus preferred recipients of technology transfers. To determine which limitations and particularities prevail in the local system of knowledge exchange, we will analyse the firms' views on the local situation and benchmark their assessment against that of companies in a potentially more favourable — and less specifically Chinese environment. To the authors' knowledge, no study has so far been conducted from this particular perspective.

More specifically, the empirical analysis will focus on a sub-group of firms which can be assumed to be part of Beijing's existing local network of technology-related inter-personal relations. To that end, the study focuses on firms which have either tried to register as "technology-firms" or applied for funding for "technology activities". To determine whether the technology transfer system in Beijing still displays "Chinese particularities" and "typically Chinese obstacles" the Beijing firms' assessment of their own situation and the local framework conditions were benchmarked against a representative sample of German firms which claim to be "innovative". Germany was selected as a country of reference as, firstly, it is an economy for which technology-based innovation is crucial for competitive success and can thus be expected to be a notion understood by most entrepreneurs and, secondly, it is an economy in which a co-operative approach to technological development and R \& D is fairly widespread (Schmoch, 2000). Thus, the Chinese firm's assessments of a number of technology-transfer related issues in their specific environment will be compared against those of a sample of innovating firms from a stable environment in which knowledge, technology and innovation have undisputedly become central to economic success and where co-operation and knowledge transfer constitute relevant sources of international competitiveness.

In the following we specify this paper's objectives by means of five distinct hypotheses.

As a first hypothesis, we suggest that the overall level of technological capability in the Chinese industrial sector is more limited than that of innovating firms in Germany, even among those companies registered as "technology firms" (Lee et al., 2011; OECD, 2008). In particular, the literature suggests that not many firms have moved into a position from which they can develop and patent global novelties (Kroll, 2011). Instead, they are more likely to focus their technological activities on the domestic market (Schiller \& Kroll, 2013) which, for the time being, offers sufficient volume and business opportunities based on the adaptation of solutions that are available elsewhere. Consequently, most of the firms surveyed in China have only recently begun to feel a need to invest substantially in own, internal R \& D capabilities, if at all. Instead, they are likely to be used to rely on external inputs and inspiration which they then transfer into actual products (Lee et al., 2011; Zhu \& Chen, 2006).

Hypothesis 1: Chinese firms looking to register as technology firms display lower technological capabilities than innovating firms in Germany-illustrated by their more limited tendency to develop global novelties; in line with this, they tend to be more dependent on external knowledge transfer and likely to place less confidence into their own, internal R \& D capacities.

As a second hypothesis, we suggest that, due to the way in which the sample was drawn, many of the surveyed firms are likely to orient their internal structure towards the requirements put forward by the government for the funding or registration that they sought to obtain. According to local experts, these include stipulations regarding the formal qualification of the staff and the official number of dedicated R \& D personnel. On the other hand, much of the literature on technology transfer in China suggests that many employees do not yet possess the necessary qualifications needed to process external technological knowledge (Cao, 2004; Tagscherer et al., 2012). In addition, many firms are said to lack market related knowledge, which leads to difficulties in selling their products (Kroll \& Schiller, 2010). Consequently, we can expect that their declared motivations for absorbing knowledge will suggest that a number of internal capabilities leave room for improvement, in particular those related to employees' qualification and to the applicability and customer orientation of their products.

Hypothesis 2: Most Chinese firms looking to register as technology firms will fulfill official "high-tech" criteria with a view to workforce qualification, R \& D employment to a stronger extent than German firms; nonetheless, some of their motivations for accessing external knowledge will indicate that their workforce's task-related qualification and customer orientation remain to be improved.

As a third hypothesis, we put forward that while many Chinese technology firms may be quite experienced with regard to the adoption and adaptation of external knowledge, a not uncommon narrative suggests that much of this absorption of knowledge is based on the re-engineering of existing hardware, rather than on an actual capability to either process more abstract, codified knowledge or to collaborate with partners from academia 
(Tagscherer et al., 2012; Wu \& Zhou, 2012). While the trade of embedded technological content has been established for more than a decade and seems to function rather well (Gu, 1999; Kroll \& Liefner, 2008), recent studies have confirmed that the actual impact of university-industry relations depends on the firms' actual investment in their own absorptive capacity (Brehm \& Lundin, 2012). Furthermore, less positive assessments have been published of Chinese universities' ability to license patents (Wu, 2010b) and of Chinese firms' general ability to absorb external knowledge (Liu \& Zheng, 2011) which in the past has prompted the emergence of an overly entrepreneurial technology transfer system (Eun et al., 2006; Kondo, 2003) that seems different from the personal-interaction-based German system (Schmoch, 2000).

Hypothesis 3: The firms surveyed in China have a lower absorptive capacity than those in the German sample; hence, many of them will seek to obtain ready-made products and prototypes; co-operative R \& D, in contrast, will remain less common.

As a fourth hypothesis, we suggest that many Chinese firms are still "national champions" neither able nor willing to compete on the global marketplace (Lee, 2005; Liu \& Zheng, 2011). For the time being, the domestic market offers sufficient volume and opportunity as well as a slightly less discerning customer base that matches the firms' own technological capabilities well (Schiller \& Kroll 2013). While capabilities relevant for global competiveness can only be learned abroad (Zhu \& Chen, 2006), this domestic market could for a transitory period be served without intensive localised R \& D co-operation. Increasingly, however, the development of novel products for a more and more challenging customer base requires an interaction with partners knowledgeable about technology but arguably also about local specifics and customer requirements (Fu et al., 2012; Schiller \& Kroll, 2013). As a result, it would seem logical if Chinese technology firms have a stronger tendency to co-operate with domestic partners than their much more internationally oriented German counterparts.

Hypothesis 4: The activities of Chinese firms looking to register as technology firms are mostly focused on the domestic market; due to this focus, the degree of $\mathrm{R} \& \mathrm{D}$ collaboration with local partners will also be higher.

Finally, much of the literature suggests that different-i.e. by and large more obstructive-framework conditions for technology transfer and knowledge exchange continue to persist in the Chinese innovation system. Beyond cultural particularities (Fu et al., 2012), examples of those framework conditions are a fragmentation of and lack of co-operative culture in the industrial sector, a general lack of awareness regarding IPR issues, a limited impartiality of some courts which leads to a limited implementation of IPR regulations, as well as a lack of managerial competences related to innovation within Chinese firms themselves (Cao, 2004; Zhu \& Chen, 2006). If all those claims hold true, it can be expected that Chinese companies encounter remarkably different obstacles in their attempts to obtain external knowledge as much as they can be expected to express different demands with a view to policy makers in charge of amending the situation.

Hypothesis 5: Due to different framework conditions, the difficulties encountered by Chinese technology firms in obtaining external knowledge differ substantially from those encountered by innovating firms in Germany; as a result, their expressed demands with a view to desirable policy support will be different.

In the following, these five main hypotheses will be tested through the empirical collection of relevant datasets in both China and Germany.

\section{Empirical Approach and Data}

To obtain the companies assessment of technology related issues, two surveys were conducted in Germany and Beijing with identical questionnaires in the respective national languages. The questionnaires comprised four main sections related to basic company information, the firms' current innovative efforts, actual and desired technology transfer activities in the firm, opinions and expectations regarding external knowledge sourcing, as well as the respondents' expectations with a view to policy. Overall, the questionnaire contained seventeen questions. With a view to the delineation of the potential survey population and the criteria relevant for the inclusion of firms into the sample, different approaches had to be chosen, due to the different framework conditions in Germany and Beijing. Both surveys were conducted in mid-2011.

In Beijing, the survey was conducted on paper and, in part, in person. In line with the conceptual approach, the sample was stochastically drawn from the management databases of government management departments dealing with the certification of company-based R \& D agencies and the allocation of public R \& D funding for enterprises. Naturally, most of the firms listed in their databases have acquired or are attempting to acquire either a certification for internal R \& D agencies by the Beijing Municipal S \& T Commission or public funding for innovation activities. As foreign-invested firms are usually not eligible for this type of public support, the 
overwhelming majority of these firms can be considered Chinese rather than foreign-invested. To the contrary, a bias for state-owned firms can not necessarily be expected as many public support programmes try to intentionally focus on supporting private as much as publicly-owned enterprises. As intended, the firms surveyed in Beijing reflect a subset of the firm population which is comparatively active in innovation and likely to be part of the established network. Arguably, they thus constitute a (fairly) representative element of the "islands of innovation" in large urban centres that have been referred to in the introduction earlier literature. As most interviews were conducted in person and the survey had the support of the authorities in Beijing, a high response rate could be achieved, resulting in an overall sample size of 178 questionnaires.

In Germany, the survey was run as an online survey based on electronic questionnaires and email, using the EFS survey software. The overall population of addressees was drawn from the Amadeus/Markus firm database. While this database does not provide complete coverage of all firms, it is not known to have any particular bias. Firms listed with less than 25 employees were excluded as information on them is often known to be less reliable or dated. Beyond that, no further stipulations were laid down, so that the potential survey population covered about 39,000 firms across Germany. Of those, 450 started to fill out the questionnaire and 265 completed it, leading to an overall response rate of $1.5 \%$. Despite this comparatively low turnout, the general representativeness of the sample could be confirmed across regions, firm sizes and industrial sectors. Later on, the sample was filtered so that only those firms which indicated to be innovative remained, limiting the sample to 120 to 140 answers, depending on the question.

In theory, broad-based online surveys have a higher tendency to become subject to self-selection bias than focused paper surveys accompanied by visits, as those addressees who are not interested in the topic can simply choose not to participate. As a result, a bias in favour of more innovative or more transfer-active firms could result. Based on a descriptive analysis of the two datasets, however, no obvious evidence for such a self-selection bias can be found. It can be confirmed that both the German and the Chinese sample cover a broad range of sectors so that is unlikely that any specific sector-or technology-related bias will come into play. Beyond that, there is no particular size-related bias in either one of the samples. On average, companies in the samples employ between 50 and 250 staff, while both smaller and larger numbers of employees are common. One major different between the two samples is that the sales volume of German firms is notably higher. On average, their turnover reaches 5 - 50 million euros whereas it ranges between 1 - 10 million euros in China. Against the background of similar employment figures, it thus seems that German are somewhat better established in their potential markets, or that, quite simply, their staff is more productive and efficient.

In the following, the significance of the differences between findings will be determined by standard t-tests of the difference of the two independent samples' means. While the nature of the survey does not necessarily suggest that all variable meet all criteria for a t-test in finite samples of limited size, the probability of a positive answer to many of the questions (arguably about 0.5) suggests that their overall probability distribution will converge against normality with a rate that makes the t-test a suitable choice at sample sizes around $n=130$.

\section{Results}

\section{Hypothesis 1: Lower Innovative Capacity, Higher Dependence on External Technology}

With a view to Hypothesis 1, our analysis finds that $81 \%$ of the firms surveyed in Germany sell products or services that can be regarded as international novelties, while two thirds of the Beijing firms offer products or services that are new to the domestic market, but exist in similar form elsewhere. In line with these more modest ambitions and/or capabilities most Chinese firms express a notably higher need for external knowledge sourcing than their German counterparts (cf. Table 1). Moreover, the results presented in Table 2 underline that these statements do not only hold in general terms but also in relation to the firms' assessment of their own internal $\mathrm{R}$ \& D effort. Whilst in Germany external knowledge tends to be assigned an only somewhat more than "medium" importance in relation to their own capabilities, most Chinese firms regard technology transfer as "highly", i.e. more, important than their own internal R \& D efforts.

Hypothesis 2: Fulfilling High-tech-Criteria while Stating Need for Improvement

With regard to Hypothesis 2, Table 3 illustrates that more than two thirds of the surveyed firms in China employ more than $50 \%$ of staff with a higher education degree while the average in Germany remains in the area of $5 \%$ - 24\%. Furthermore, Table 4 highlights that Chinese firms have a significantly higher tendency to employ staff as dedicated R \& D personnel than their German counterparts. Contrarily, Table 5 highlights that the factors that motivate companies to seek technology transfers are in general not very different. There are, however, 
Table 1. Stated relevance of technology transfer/external knowledge.

\begin{tabular}{|c|c|c|c|c|c|}
\hline & Very high & High & Medium & Low & Very low \\
\hline China (Beijing), $\mathrm{n}=128$ & $46.9 \%$ & $50.8 \%$ & $2.3 \%$ & $0.0 \%$ & $0.0 \%$ \\
\hline Germany, $n=133$ & $9.0 \%$ & $39.1 \%$ & $39.1 \%$ & $12.0 \%$ & $0.8 \%$ \\
\hline Difference significant & \multicolumn{5}{|c|}{ Yes, at 99.9\% level (CN: 1.55, DE: 2.56) } \\
\hline
\end{tabular}

Source: Own table based on empirical analysis.

Table 2. Stated relevance of external knowledge compared to own R \& D efforts.

\begin{tabular}{|c|c|c|c|c|c|}
\hline & Very high & High & Medium & Low & Very low \\
\hline China (Beijing), $\mathrm{n}=128$ & $38.3 \%$ & $52.3 \%$ & $9.4 \%$ & $0.0 \%$ & $0.0 \%$ \\
\hline Germany, $\mathrm{n}=133$ & $8.3 \%$ & $31.6 \%$ & $46.6 \%$ & $12.8 \%$ & $0.8 \%$ \\
\hline Difference significant & \multicolumn{5}{|c|}{ Yes, at 99.9\% level (CN: 1.71, DE: 2.66) } \\
\hline
\end{tabular}

Source: Own table based on empirical analysis.

Table 3. Share of employees with higher education degree.

\begin{tabular}{|c|c|c|c|c|}
\hline & $1 \%-4 \%$ & $5 \%-24 \%$ & $25 \%-49 \%$ & above $50 \%$ \\
\hline China (Beijing), $\mathrm{n}=128$ & $0.0 \%$ & $14.1 \%$ & $18.0 \%$ & $68.0 \%$ \\
\hline Germany, $n=120$ & $22.5 \%$ & $54.2 \%$ & $15.0 \%$ & $8.3 \%$ \\
\hline Difference significant & \multicolumn{4}{|c|}{ Yes, at $99.9 \%$ level (CN: 3.54, DE: 2.09) } \\
\hline
\end{tabular}

Source: Own table based on empirical analysis.

Table 4. Share of employees working full-time as dedicated R \& D staff.

\begin{tabular}{|c|c|c|c|c|c|}
\hline & None & Below 10\% & $10 \%-24 \%$ & $25 \%-49 \%$ & Above 50\% \\
\hline China (Beijing), $\mathrm{n}=127$ & $0.8 \%$ & $9.4 \%$ & $33.9 \%$ & $22.8 \%$ & $33.1 \%$ \\
\hline Germany, $n=136$ & $28.7 \%$ & $38.2 \%$ & $25.0 \%$ & $5.1 \%$ & $2.9 \%$ \\
\hline Difference significant & \multicolumn{5}{|c|}{ Yes, at 99.9\% level (CN: 3.78, DE: 2.15) } \\
\hline
\end{tabular}

Source: Own table based on empirical analysis.

Table 5. Main purpose of seeking technology transfer as stated by company.

\begin{tabular}{|c|c|c|c|}
\hline & 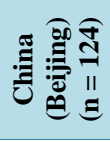 & 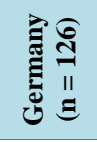 & 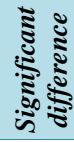 \\
\hline Increase degree of novelty of products/services & $75.8 \%$ & $65.9 \%$ & $\circ$ \\
\hline Increase of own R\&D competence through learning effects & $75.0 \%$ & $65.9 \%$ & - \\
\hline Increase qualification of own personnel & $54.0 \%$ & $31.7 \%$ & $* * *$ \\
\hline Improve adaptation to customer requirements & $51.6 \%$ & $42.9 \%$ & - \\
\hline Improve quality of existing products/services & $39.5 \%$ & $38.9 \%$ & - \\
\hline Improve marketing and advertisement strategies & $29.8 \%$ & $13.5 \%$ & $* * *$ \\
\hline Increase ability to flexibly respond to customer requirements & $20.2 \%$ & $26.2 \%$ & - \\
\hline Lower production cost & $1.6 \%$ & $29.4 \%$ & $* * *$ \\
\hline
\end{tabular}

o(significant) at 90\% level, ${ }^{*}$ significant at $95 \%$ level, ${ }^{* *}$ significant at $99 \%$ level, ${ }^{* * *}$ significant at 99 , 9\% level. Note: A maximum of three different types of competitive edge could be stated. Source: Own table based on empirical analysis. 
some notable differences regarding the need to "increasing the qualification of own personnel" suggesting that the formal qualifications of the firms' employees (Table 3) are of limited value to the firms' actual business. Furthermore, a pronounced wish to "improve marketing and advertisement strategies" suggests that such market-related competences are not available within the firms themselves.

Hypothesis 3: Low Absorptive Capacity, Limited Transfer Channels, Focus on Public Partners

Concerning Hypothesis 3, Table 6 corroborates that it is significantly more common among the surveyed technology firms in China to obtain either prototypes or readily developed products from external sources than it is among innovating firms in Germany. On the other hand, this does not imply that a significantly lower number of them focus on obtaining patents or drawing information from relevant scientific publications. As it seems, many Chinese firms tend to add a complementary aspect to their activities rather than opting for a completely different profile.

In line with this, Table 7 illustrates that the patterns of technology transfer channels used by Chinese and German firms are in fact surprisingly similar. More precisely, we find those approaches based on personal contacts and collaboration dominant in both countries. Nonetheless, Chinese firms do indeed display a higher propensity to license patents as well as they focus more often on the hiring of additional R \& D staff and the outsourcing of R \& D projects as channels of transfer.

Hypothesis 4: Orientation of Knowledge Sourcing towards Domestic Source

As for Hypothesis 4, Table 8 unsurprisingly confirms that a substantially higher share of the, on average, technologically more advanced firms in Germany sells on the global market, while a dominant share of the Chi-

Table 6. Main type of knowledge obtained.

\begin{tabular}{|c|c|c|c|}
\hline & 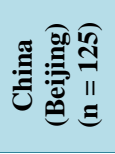 & 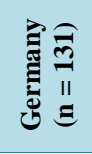 & 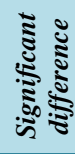 \\
\hline Basic scientific knowledge (Publications) & $44.8 \%$ & $49.6 \%$ & - \\
\hline Basic technological knowledge (Patents) & $68.8 \%$ & $58.8 \%$ & $\circ$ \\
\hline Prototypes & $48.8 \%$ & $22.9 \%$ & *** \\
\hline Readily developed products & $59.2 \%$ & $26.0 \%$ & *** \\
\hline
\end{tabular}

${ }^{\circ}$ (significant) at $90 \%$ level, ${ }^{*}$ significant at $95 \%$ level, ${ }^{* *}$ significant at $99 \%$ level, ${ }^{* * *}$ significant at $99,9 \%$ level. Note: A maximum of three different types of competitive edge could be stated. Source: Own table based on empirical analysis.

Table 7. Main channels used to obtain external knowledge, main partners.

\begin{tabular}{|c|c|c|c|}
\hline & 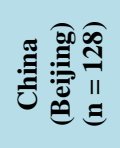 & 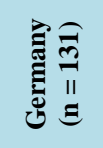 & 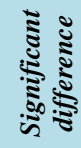 \\
\hline Joint development of solutions in R \& D co-operations & $76.6 \%$ & $66.4 \%$ & $\circ$ \\
\hline Consultancy of internal developers by external experts & $58.6 \%$ & $43.5 \%$ & * \\
\hline Training of own personnel with a view to R \& D competences & $49.2 \%$ & $52.7 \%$ & - \\
\hline Permanent hiring of new personnel with R \& D capabilities & $36.7 \%$ & $30.5 \%$ & - \\
\hline Temporary hiring of ext. personnel with R \& D capabilities & $36.7 \%$ & $6.9 \%$ & $* * *$ \\
\hline Licensing of existing (invention) patents & $35.9 \%$ & $11.5 \%$ & $* * *$ \\
\hline Provision of results developed in the course of past projects & $26.6 \%$ & $27.5 \%$ & - \\
\hline Outsourcing of R \& D projects & $19.5 \%$ & $9.9 \%$ & * \\
\hline Licensing of existing utility models & $9.4 \%$ & $0.0 \%$ & $* * *$ \\
\hline
\end{tabular}

o(significant) at $90 \%$ level, ${ }^{*}$ significant at $95 \%$ level, ${ }^{* *}$ significant at $99 \%$ level, ${ }^{* * *}$ significant at $99,9 \%$ level. Note: A maximum of three different types of competitive edge could be stated. Source: Own table based on empirical analysis. 
nese firms focuses on the domestic market. This, however, is not necessarily reflected in their selection of R \& $\mathrm{D}$ co-operation partners as the share of firms maintaining contacts with firms, universities or public research institutes abroad does not differ significantly from that of German firms. With a view to their choice of domestic partners, we indeed find a significantly higher propensity to collaborate with public research organisations or universities as well as a significantly lower prevalence of co-operations with business partners.

Hypothesis 5: Different Obstacles Resulting from Different Framework Conditions

Hypothesis 5, finally, can surprisingly not be confirmed. In fact, very few significant differences can be identified, even with regard to those issues clearly associated with the assumed Chinese situation such as "organisational problems", "lack of sufficiently qualified personnel", "inadequate legislation, regulations", and "reservations regarding reliability of partners in the IPR-field" (cf. Table 9). Instead, the most notable difference identi-

Table 8. Main market orientation and main orientation of knowledge sourcing.

\begin{tabular}{|c|c|c|c|}
\hline & 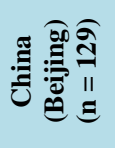 & 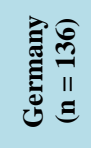 & 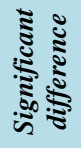 \\
\hline National Market & $92.2 \%$ & $44.1 \%$ & *** \\
\hline International Market (technologically leading economies) & $12.4 \%$ & $75.7 \%$ & $* * *$ \\
\hline International Market (developing and emerging economies) & $13.2 \%$ & $16.9 \%$ & - \\
\hline Domestic Public Research/University Partner & $\mathbf{8 6 . 0} \%$ & $60.3 \%$ & *** \\
\hline International Public Research/University Partner & $20.9 \%$ & $12.5 \%$ & $\circ$ \\
\hline Domestic Business Partner (excl. consultants) & $55.9 \%$ & $70.5 \%$ & $* * *$ \\
\hline International Business Partner (excl. consultants) & $46.3 \%$ & $36.4 \%$ & - \\
\hline
\end{tabular}

${ }^{\circ}$ (significant) at $90 \%$ level, ${ }^{*}$ significant at 95\% level, ${ }^{* *}$ significant at $99 \%$ level, ${ }^{* * *}$ significant at 99 , 9\% level. Note: A maximum of three different types of competitive edge could be stated. Source: Own table based on empirical analysis.

Table 9. Main difficulties encountered with regard to knowledge sourcing.

\begin{tabular}{|c|c|c|c|}
\hline & 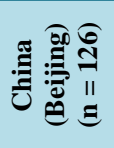 & 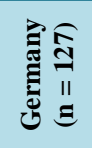 & 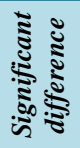 \\
\hline Lack of public support with a view to subsidy programmes & $63.5 \%$ & $14.2 \%$ & $* * *$ \\
\hline Lack of internal sources of finance & $39.7 \%$ & $15.7 \%$ & *** \\
\hline Excessive cost (unfavourable cost-benefit analysis) & $34.9 \%$ & $37.8 \%$ & - \\
\hline Organisational problems during the process of realisation & $22.2 \%$ & $28.3 \%$ & - \\
\hline Lack of information on suitable co-operation partners & $22.2 \%$ & $20.5 \%$ & - \\
\hline Inadequate legislation, regulations, administrative procedures & $19.0 \%$ & $12.6 \%$ & - \\
\hline Lack of sufficiently qualified personnel & $15.9 \%$ & $23.6 \%$ & - \\
\hline Reservations regarding reliability of partners in the IPR-field & $15.9 \%$ & $19.7 \%$ & - \\
\hline Lack of suitable external sources of finance & $11.1 \%$ & $11.8 \%$ & - \\
\hline Lack of suitable co-operation partners & $11.1 \%$ & $19.7 \%$ & $\circ$ \\
\hline Lack of interest on the side of potential co-operation partners & $4.0 \%$ & $4.7 \%$ & - \\
\hline Internal resistance to/reservations against R\&D-cooperation & $1.6 \%$ & $6.3 \%$ & $\circ$ \\
\hline
\end{tabular}

${ }^{\circ}$ (significant) at $90 \%$ level, ${ }^{*}$ significant at $95 \%$ level, ${ }^{* *}$ significant at $99 \%$ level, ${ }^{* * *}$ significant at $99,9 \%$ level. Note: A maximum of three different types of competitive edge could be stated. Source: Own table based on empirical analysis. 
fied by the surveys was that it was substantially more common among Chinese firms to perceive a "lack of internal sources of finance" and to lament a "lack of public support". Apparently, many of the surveyed technology firms are often more worried about their ability to finance R \& D than about their own internal capabilities to absorb and process external knowledge and the external framework conditions that enable them to do so.

\section{Discussion}

Evidently, most of our findings have been found to be in line with our general assumptions while some of our assumptions could be proved to be wrong. What has been confirmed for the surveyed sample in the Beijing area is the overall picture of a set of technologically-learning, domestically-oriented firms that are still less established in their potential markets than the average firm in a technologically well-developed nation. Arguably, much external knowledge still feeds into routines of re-engineering and adaptation rather than inspiring a genuine process of new product development.

Likewise, we find evidence of a state-driven model of technological upgrading, documented by the high extent of fulfilling formal criteria and an apparent lack of ability or interest to shift the main business model by own initiative. Instead, many of the surveyed firms deplore their lack of internal resources to launch R \& D activities and call for the government to provide these-arguably instead of prioritizing their own investment strategy accordingly.

Interestingly, however, this combination of limited technological capacities as well as limited internal resources of various kinds seems to have added momentum to, rather than obstructed, the development of a dense network of R \& D co-operation and technology transfer. Beyond certain Chinese particularities, most of the firms surveyed in Beijing are driven by quite similar motivations and use the same channels of technology transfer as their German counterparts. Apparently, both rely intensively on pre-existing networks of personal contacts even if those may at times be of a quite different nature.

In general terms, the majority of the surveyed firms were implicitly very optimistic with regard to their ability to, if necessary, obtain relevant external knowledge. Contrary to commonly accepted wisdom, neither the institutional framework conditions nor the characteristics of their potential partners were seen as major obstacles. Instead, many firms claimed that they had problems with establishing internal R \& D capacities and did not consider technology transfer as such as an appropriate means to that end.

If these findings are taken at face value, they seem to question many of the established findings on a 'stalled' or at least heavy going process of technology transfer from Chinese universities to the regional enterprise sector. They should, however, be put into perspective from two different angles.

Firstly, we have to take into account which subsample of the overall population of enterprises has been surveyed. Evidently, we are talking about a sub-group of even those firms that have the advantage to operate on the "Beijing island of innovation". Many of them are likely to have had long-standing inter-personal relations with many of their current R \& D co-operation partners long before the challenge of launching more innovationoriented projects had become an issue. Possibly, a number of them even are former public R \& D institutes which have been privatised and turned into private R \& D service providers in the late 1990s. Among many of those players, issues of mutual trust or distrust will have been resolved years ago—and help to circumvent many of the limitations related to framework conditions that may in general terms still be present.

Secondly, it has to be acknowledged that while many firms stated that their networkedness and access to external knowledge was not bad, they still stated an internal level of technological competence that must appear dissatisfactory to many of. What we find lacking, therefore, is the combination of internal R \& D capacity, relevant task-related qualification and good access to external knowledge that was found to be characteristic for German firms. As long as many of the Chinese firms have not launched substantial internal R \& D activities, external knowledge will merely be fed into established processes of adapting existing products instead of inspiring genuinely novel, globally relevant developments.

Hence, our findings do not refute the statement that the current system of technology transfer continues to display a fairly limited capability to support industrial upgrading in China. What they suggest, in contrast, is that the degree of connectedness to external partners is not (always) the main issue.

\section{Summary and Conclusion}

In summary, our study has highlighted that technology transfer systems in China may involve more channels, involve more partners, and in global terms be more dynamic than commonly assumed—at least in the case of 
well-developed urban innovation systems such as Beijing. Our survey documents a vibrant set of interactions not only between science and industry but also up and down the value chain. Moreover, most of the surveyed companies could not find fault with many of the commonly assumed obstacles to knowledge exchange in China — such as lack of trust or unfavourable and poorly implemented regulations. Despite these surprising findings, other results of the survey still underline that most of the firms that the government registers as "technology-enterprises", continue to predominantly sell on and develop for the domestic market. Despite an impressive share of R \& D staff in their workforce, many of them still lack a well-established internal R \& D process and are only starting to develop sufficient absorptive capacity to become able to integrate more complex and abstract forms of external knowledge. In brief, technology transfer in China fails to achieve the complementary, inspiring function that it fulfils in many technologically more developed economies.

In conclusion, more has been achieved with regard to technology transfer in (at least some parts of) China than is commonly acknowledged, even though it is correct that the results remain less than convincing. Certainly, one has to remain sceptical with regard to the firms' own claim that money alone will solve much of the remaining problem of limited internal capacities. On the other hand, we find tentative evidence that a good number of them are silently working in parallel on the less monetary issues such as qualification and market orientation.

Undoubtedly, many of China's “technology companies" have a long way to go before they can develop the technological capacity needed to compete on the global markets-should they at all ever aim to do so. By focusing one of the more advanced sub-set of technology firms, however, this article has collected tangible evidence that cautions against underestimating the inherent potential of science-industry relations in China. In fact, it would even today be more appropriate to speak of a potential to expand current practices rather than a dormant potential. In a few years' time, a much more substantial number of Chinese firms will likely have developed internal capacities in line with those found in our Beijing sub-sample-while their interpersonal networks of knowledge exchange will certainly be no weaker than today.

\section{Acknowledgements}

We acknowledge the contribution of the Beijing Research Centre for Science of Science (BJAST-BRCSS) that has not only financed part of this research but also implemented the empirical study in China. In particular, we acknowledge the support of Dr. Zhang Shiyun and the contributions of Chang Jing and others who had a substantial part in compiling the Chinese dataset. Furthermore, we thank an anonymous internal reviewer for critical yet constructive comments on a first draft of this paper.

\section{References}

Altenburg, T., Schmitz, H., \& Stamm, A. (2008). Breakthrough? China’s and India’s Transition from Production to Innovation. World Development, 36, 325-344. http://dx.doi.org/10.1016/j.worlddev.2007.06.011

Asian Development Bank (ADB) (2010). Asia 2050: Realizing the Asian Century. Metro Manila: Asian Development Bank (ADB).

Bozeman, B. (2000). Technology Transfer and Public Policy: A Review of Research and Theory. Research Policy, 29, 627655. http://dx.doi.org/10.1016/S0048-7333(99)00093-1

Bozeman, B., Fay, D., \& Slade, C. P. (2013). Research Collaboration in Universities and Academic Entrepreneurship: TheState-of-the-Art. Journal of Technology Transfer, 38, 1-67. http://dx.doi.org/10.1007/s10961-012-9281-8

Brehm, S., \& Lundin, N. (2012). University-Industry Linkages and Absorptive Capacity: An Empirical Analysis of China's Manufacturing Industry. Economics of Innovation and New Technology, 21, 837-852. http://dx.doi.org/10.1080/10438599.2012.687503

Cao, C. (2004). Zhongguancun and China’s High-Tech Parks in Transition: “Growing Pains” or "Premature Senility”? Asian Survey, 44, 647-668. http://dx.doi.org/10.1525/as.2004.44.5.647

Cao, C., Suttmeier, R. P., \& Simon, D. F. (2006). China’s 15-Year Science and Technology Plan. Physics Today, 54, 38. http://dx.doi.org/10.1063/1.2435680

Chen, K., \& Kenney, M. (2007). Universities/Research Institutes and Regional Innovation Systems: The Cases of Beijing and Shenzhen. World Development, 35, 1056-1074. http://dx.doi.org/10.1016/j.worlddev.2006.05.013

Chen, Y.-C. (2007). The Upgrading of Multinational Regional Innovation Networks in China. Asia Pacific Business Review, 13, 373-403. http://dx.doi.org/10.1080/13602380701291941

Cohen, W. M., \& Levinthal, D. A. (1990). Absorptive Capacity: A New Perspective on Learning and Innovation. Adminis- 
trative Science Quarterly, 35, 128-152. http://dx.doi.org/10.2307/2393553

D’Este, P., \& Patel, P. (2007). University-Industry Linkages in the UK: What Are the Factors Underlying the Variety of Interactions with Industry? Research Policy, 36, 1295-1313. http://dx.doi.org/10.1016/j.respol.2007.05.002

Dosi, G. (1988). The Nature of the Innovation Process. In G. Dosi, C. Freeman, R. Nelson, G. Silverberg, \& L. Soete (Eds.), Technical Change and Economic Theory (pp. 221-238). London: Pinter.

Eun, J.-H., \& Lee, K. (2010). An Empirical Inquiry into “Academy-Run Enterprises” in China: Unique Characteristics and Evolutionary Changes. International Journal of Innovation Management, 14, 123-150. http://dx.doi.org/10.1142/S136391961000257X

Eun, J.-H., Lee, K., \& Wu, G. (2006). Explaining the “University-Run Enterprises” in China: A Theoretical Framework for University-Industry Relationship in Developing Countries and Its Application to China. Research Policy, 35, $1329-1346$. http://dx.doi.org/10.1016/j.respol.2006.05.008

Frietsch, R., \& Schüller, M. (2010). Competing for Global Innovation Leadership: Innovation Systems and Policies in the USA, Europe and Asia. Stuttgart: Fraunhofer Verlag.

Frietsch, R., Hinze, S., \& Tang, L. (2008). Bibliometric Data Study: Assessing the Current Ranking of the People's Republic of China in a Set of Research Fields. Discussion Papers Innovation System and Policy Analysis No. 15. Karlsruhe: Fraunhofer ISI.

Fu, W., Schiller, D., \& Revilla Diez, J. (2012). Strategies of Using Social Proximity and Organizational Proximity in Product Innovation: Empirical Insight from the Pearl River Delta, China. Zeitschrift für Wirtschaftsgeographie, 56, 80-96.

Gu, S. (1999). Implications of National Innovation Systems for Developing Countries: Managing Change and Complexity in Economic Development. UNU/INTECH Discussion Paper 9903. Maastricht: UNU/INTECH.

Guan, J. C., Yam, R. C. M., \& Mok, C. K. (2005). Collaboration between Industry and Research Institutes/Universities on Industrial Innovation in Beijing, China. Technology Analysis and Strategic Management, 17, 339-353. http://dx.doi.org/10.1080/09537320500211466

Intarakumnerd, P., Chairatana, P., \& Tangchitpiboon, T. (2002). National Innovation System in Less Successful Developing Countries: The Case of Thailand. Research Policy, 31, 1445-1457. http://dx.doi.org/10.1016/S0048-7333(02)00074-4

Jin, F., Lee, K., \& Kim, Y.-K. (2008). Changing Engines of Growth in China: From Exports, FDI and Marketization to Innovation and Exports. China and World Economy, 16, 31-49. http://dx.doi.org/10.1111/j.1749-124X.2008.00105.X

Kodama, F., \& Branscomb, L. M. (1999). University Research as an Engine for Growth: How Realistic Is the Vision? In L. M. Branscomb, F. Kodama, \& R. Florida (Eds.), Industrializing Knowledge: University-Industry Linkages in Japan and the United States (pp. 3-19). London: MIT Press.

Kondo, M. (2003). The Chinese Model to Create High-Tech Start-Ups from Universities and Research Institutes. In M. von Zedtwitz, G. Haour, T. M. Khalil, \& L. A. Lefebvre (Eds.), Management of Technology: Growth through Business Innovation and Entrepreneurship - The Tenth International Conference on Management of Technology. Oxford: Pergamon.

Kroll, H. (2010). Indicator-Based Reporting on the Chinese Innovation System 2010-The Regional Dimension of Science and Innovation in China. Karlsruhe: Fraunhofer ISI.

Kroll, H. (2011). Exploring the Validity of Patent Applications as an Indicator of Chinese Competitiveness and Market Structure. World Patent Information, 33, 23-33. http://dx.doi.org/10.1016/j.wpi.2010.03.004

Kroll, H., \& Liefner, I. (2008). Spin-Off Enterprises as a Means of Technology Commercialisation in a Transforming Economy-Evidence from Three Universities in China. Technovation, 28, 298-313. http://dx.doi.org/10.1016/j.technovation.2007.05.002

Kroll, H., \& Schiller, D. (2010). Establishing an Interface between Public Sector Applied Research and the Chinese Enterprise Sector: Preparing for 2020. Technovation, 30, 117-129. http://dx.doi.org/10.1016/j.technovation.2009.10.003

Kroll, H., \& Schiller, D. (2012). Upgrading Strategies of Electronics Firms within the Regional Innovation System of the Pearl River Delta, Illustrated by the Example of Two Hong Kong Firms. In C. Petti (Ed.), Technological Entrepreneurship in China (pp. 41-65). Cheltenham: Edward Elgar.

Lee, K. (2005). Making a Technological Catch-Up: Barriers and Opportunities. Asian Journal of Technology Innovation, 13, 97-131. http://dx.doi.org/10.1080/19761597.2005.9668610

Lee, K., Jee, M., \& Eun, J.-H. (2011). Assessing China’s Economic Catch-Up at the Firm Level and Beyond: Washington Consensus, East Asian Consensus and the Beijing Model. Industry and Innovation, 18, 487-507. http://dx.doi.org/10.1080/13662716.2011.583463

Liefner, I., \& Schiller, D. (2008). Academic Capabilities in Developing Countries-A Conceptual Framework with Empirical Illustration from Thailand. Research Policy, 37, 276-293. http://dx.doi.org/10.1016/j.respol.2007.08.007

Liu, F., \& Zheng, G. (2011). Open Innovation in Chinese High-Tech Enterprises: An Empirical Research Based on Zhejiang Province. IEEE International Conference on Industrial Engineering and Engineering Management, Singapore City, 6-9 
December 2011, 1643-1647.

Motohashi, K. (2008). Assessment of Technological Capability in Science Industry Linkage in China by Patent Database. World Patent Information, 30, 225-232. http://dx.doi.org/10.1016/j.wpi.2007.10.006

Motohashi, K., \& Yun, X. (2007). China’s Innovation System Reform and Growing Industry and Science Linkages. Research Policy, 36, 1251-1260. http://dx.doi.org/10.1016/j.respol.2007.02.023

OECD (Ed.) (2008). Reviews of Innovation Policy: China. Paris: OECD Publications.

Quan, X. (2010). Knowledge Diffusion from MNC R \& D Labs in Developing Countries: Evidence from Interaction between MNC R \& D Labs and Local Universities in Beijing. International Journal of Technology Management, 51, 364386.

Schiller, D. (2011). The Role of Foreign and Domestic Firms in Regional Innovation Systems of Latecomer Countries: Empirical Evidence from the Electronics Industry in the Pearl River Delta. Erdkunde, 65, 23-40. http://dx.doi.org/10.3112/erdkunde.2011.01.03

Schiller, D., \& Kroll, H. (2013). The Global Economic Crisis as Leverage for Emerging Regional Growth Paths? Differentiated Evidence from China-Three Years Onwards. In S. Eriksson (Ed.), Clusters and Economic Growth in Asia (pp. 85-118). Cheltenham: Edward Elgar. http://dx.doi.org/10.4337/9780857930095.00010

Schmoch, U. (2000). Konzepte des Technologietransfers. In U. Schmoch, G. Licht, \& M. Reinhard (Eds.), Wissens-und Technologietransfer in Deutschland (pp. 3-13). Stuttgart: Fraunhofer IRB Verlag.

Segal, A. (2003). Digital Dragon. High-Technology Enterprises in China. Ithaca, London: Cornell University Press.

Tagscherer, U., Kroll, H., \& Luo, X. (2012). Regional Innovation Systems in China-An Analysis of Industry-Science Linkages in Bohai Bay Area. In C. Petti (Ed.), Technological Entrepreneurship in China (pp. 16-40). Cheltenham: Edward Elgar.

Uyarra, E. (2010). Conceptualizing the Regional Roles of Universities, Implications and Contradictions. European Planning Studies, 18, 1227-1246. http://dx.doi.org/10.1080/09654311003791275

Wang, Y., \& Zhou, Z. (2013). The Dual Role of Local Sites in Assisting Firms with Developing Technological Capabilities: Evidence from China. International Business Review, 22, 63-76. http://dx.doi.org/10.1016/j.ibusrev.2012.02.003

Wu, W. (2010a). Higher Education Innovation in China. Washington DC: The World Bank, East Asia and Pacific Region Human Development Department.

http://siteresources.worldbank.org/INTEASTASIAPACIFIC/Resources/China-Higher EducationInnovation.pdf

Wu, W. (2010b). Managing and Incentivizing Research Commercialization in Chinese Universities. The Journal of Technology Transfer, 35, 203-224. http://dx.doi.org/10.1007/s10961-009-9116-4

Wu, W., \& Zhou, Y. (2012). The Third Mission Stalled? Universities in China's Technological Progress. The Journal of Technology Transfer, 37, 812-827. http://dx.doi.org/10.1007/s10961-011-9233-8

Yang, R., \& Welch, A. (2012). A World-Class University in China? The Case of Tsinghua. Higher Education, 63, 645-666. http://dx.doi.org/10.1007/s10734-011-9465-4

Zhao, J., \& Richards, J. (2012). Beijing Innovation System: The Perspective of Organisational Structure and Spatial Distribution. International Journal of Learning and Intellectual Capital, 9, 413-428. http://dx.doi.org/10.1504/IJLIC.2012.049617

Zhu, Z., \& Chen, J. (2006). Open Innovation and Technological Learning in China. 2006 IEEE International Engineering Management Conference, Salvador, 17-20 September 2006, 483-487. http://dx.doi.org/10.1109/IEMC.2006.4279914 
Scientific Research Publishing (SCIRP) is one of the largest Open Access journal publishers. It is currently publishing more than 200 open access, online, peer-reviewed journals covering a wide range of academic disciplines. SCIRP serves the worldwide academic communities and contributes to the progress and application of science with its publication.

Other selected journals from SCIRP are listed as below. Submit your manuscript to us via either submit@scirp.org or Online Submission Portal.
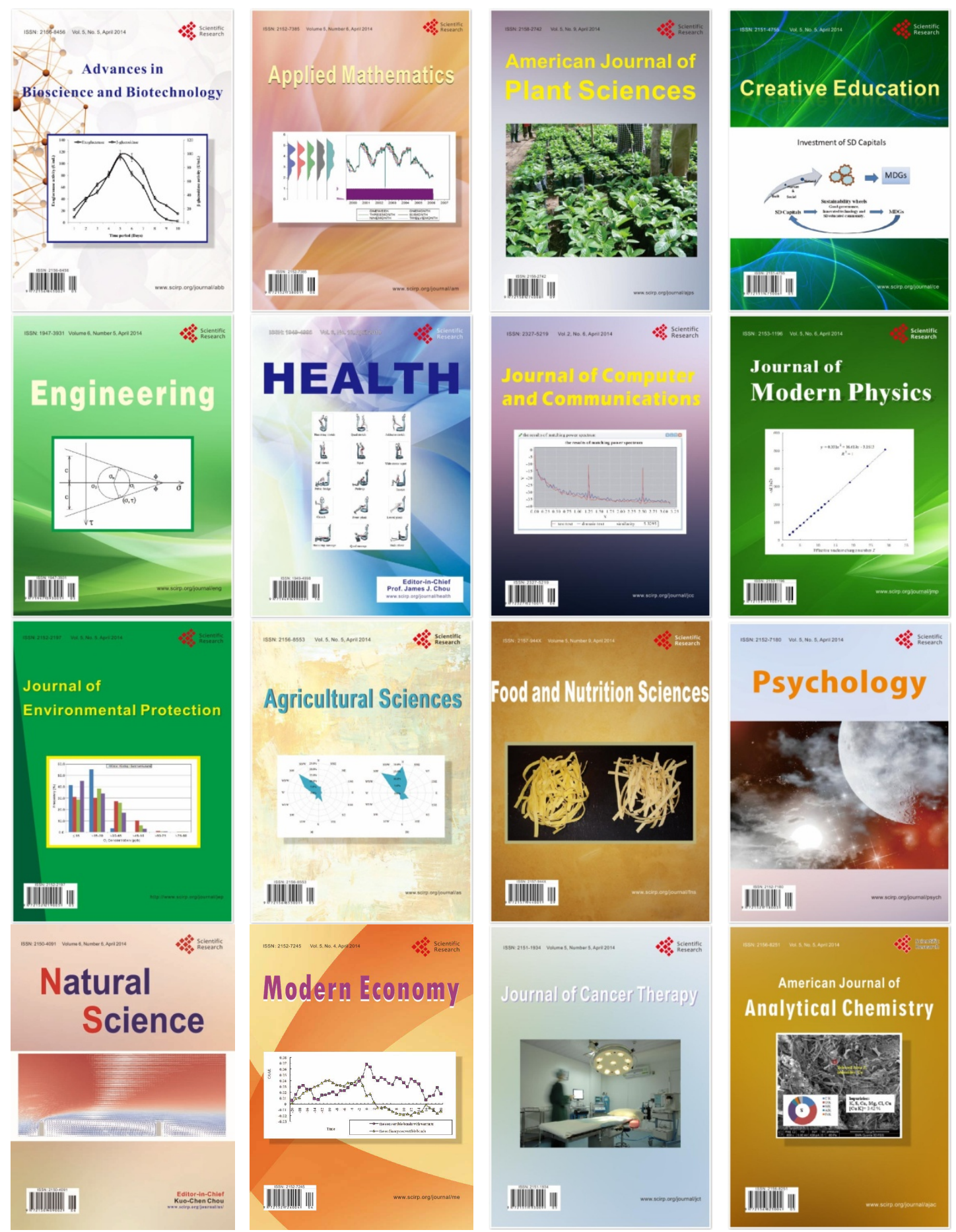